\title{
PERFIL SENSORIAL DA BEBIDA CAFÉ (Coffea arabica L.) DETERMINADO POR ANÁLISE TEMPO-INTENSIDADE ${ }^{1}$
}

\author{
Marlene A. M. MONTEIRO ${ }^{2 *}$, Valéria P. R. MINIM², Aline F. SILVA², \\ José B. P. CHAVES ${ }^{2}$, Helena Maria A. B. CARDELLO ${ }^{3}$
}

\begin{abstract}
RESUMO
O presente trabalho teve como objetivo avaliar o gosto amargo, sabor fermentado e sabor queimado de nove amostras (mole/clara, dura/clara, rio/clara, mole/expresso, dura/expresso, rio/expresso, mole/escura, dura/escura e rio/escura) da bebida café (Coffea arabica L.) por meio da análise Tempo-Intensidade (TI). Foram avaliados seis parâmetros da curva: tempo para atingir a intensidade máxima (TImáx), intensidade máxima do estímulo (Imáx), tempo correspondente ao ponto onde a intensidade máxima começa a declinar (Td), tempo de duração da intensidade máxima (Platô), área sob a curva (Área) e tempo total de duração do estímulo (Ttot). A análise demonstrou que as amostras de torra escura tiveram maior intensidade máxima (Imáx) e tempo de duração do estímulo (Ttot) para gosto amargo e sabor queimado, sendo que as amostras de torra clara apresentaram menor intensidade destes estímulos. Em relação ao sabor fermentado, a amostra rio/expresso foi a que apresentou maior intensidade.

Palavras-chave: café, análise sensorial, análise Tempo-Intensidade.
\end{abstract}

\section{SUMMARY}

SENSORIAL PROFILE OF BEVERAGE COFFEE (Coffea arabica L.) DETERMINED BY ANALYSIS TIME-INTENSITY. The present work had as objective to evaluate the bitter taste, fermented flavor and burned flavor of nine samples (soft/light, hard/light, rio/light, soft/express, hard/express, rio/express, soft/dark, hard/dark and rio/dark) of the drink coffee (Coffea arabica L.) through the analysis Time-Intensity (TI). Six parameters of the curve were evaluated: time to reach the maximum intensity (TImáx), maximum intensity of the incentive (Imáx), time corresponding to the point where the maximum intensity begins to refuse (Td), time of duration of the maximum intensity (Plateau), area under the curve (Área) and total time of duration of the incentive (Ttot). The analysis demonstrated that the samples of dark toast had larger maximum intensity (Imáx) and time of duration of the incentive (Ttot) for bitter taste and burned flavor, while the samples of light toast presented smaller intensity of these stimulus. For the fermented flavor, the sample rio/express was the one that presented larger intensity.

Keywords: coffee, sensory evaluation, time-intensity analysis.

\section{1 - INTRODUÇÃO}

Desde o século XIX, a importância da cafeicultura para o desenvolvimento econômico do Brasil é indiscutível. Porém, nas últimas décadas, o setor passou por altos e baixos, tornando imprescindível a busca pela melhoria da qualidade tanto no setor de café solúvel como no de torrado e moído, procurando ampliar não só o consumo de café no mercado brasileiro, mas, também, as exportações [9].

O sabor característico do café como bebida é proveniente do grão, estando diretamente relacionado com as variedades e influenciado por tratos agrícolas, processos de secagem, fermentação, torrefação, moagem e envase [2].

A avaliação sensorial clássica quantifica a resposta sensorial usando um ponto único de medida. Os provadores fazem uma média do tempo ou integram sua resposta para decodificarem suas respostas para um valor de intensidade único [3].

A análise Tempo-Intensidade é um prolongamento da análise sensorial clássica por meio de escalas, provida de informações temporais sobre a sensação percebida [6]. Ela quantifica a intensidade percebida de um único estímulo

\footnotetext{
${ }^{1}$ Recebido para publicação em 15/02/2005. Aceito para publicação em 05/09/2005 (001484).

${ }^{2}$ Universidade Federal de Viçosa. Departamento de Tecnologia de Alimentos. CEP: 36571-000, Viçosa - MG.

${ }^{3}$ Departamento de Alimentos e Nutrição, Faculdade de Engenharia de Alimentos, UNICAMP, CP 6121, CEP 13086-970.

*A quem a correspondência deve ser enviada.
}

de acordo com o tempo percorrido (velocidade, duração e intensidade) durante a avaliação de uma amostra.

É de suma importância a sua aplicação como forma de avaliação de um alimento, uma vez que a percepção do aroma, do sabor e da textura é um fenômeno dinâmico e não estático.

O objetivo deste estudo foi avaliar o gosto amargo, sabor queimado e sabor fermentado de três classes de café (mole, dura e rio) submetidas a diferentes tipos de torra (clara ou americana, expresso e escura), por meio da análise Tempo-Intensidade.

\section{2 - MATERIAL E MÉTODOS}

\section{1 - Matéria-prima}

As amostras de café natural das classes mole, dura e rio ( $15 \mathrm{~kg}$ de cada classe) foram adquiridas na Cooperativa INCOFEX, Viçosa - MG, Brasil. A variedade de café estudada foi a Coffea arabica L. da safra 2001/2002, colhida por derriça manual ao chão. A secagem dos grãos foi feita em terreiros que posteriormente foram armazenados em sacos de juta de $60 \mathrm{~kg}$. A classificação dos grãos quanto à bebida foi feita por meio da "prova de xícara", realizada pela Cooperativa INCOFEX.

\section{2 - Torração}

O ponto de torra foi obtido por análise tempo $\mathrm{x}$ temperatura, e por análise visual conforme descrito abaixo. 
A torração do café natural foi feita em um torrefador contínuo da marca Rod-Bel a temperaturas que variaram de 210 a $230^{\circ} \mathrm{C}$ por 9 a 12 minutos de acordo com cada tipo de torra. A medição da temperatura foi feita utilizando termômetro de $360^{\circ} \mathrm{C}$, sendo efetuada ao final de cada torra. Este torrefador era constituído de tambores giratórios, e cada tambor possuía uma fornalha com um sistema de resfriamento.

De acordo com testes preliminares, foram escolhidos o tambor e a fornalha que possuíam chama homogênea e melhor padronização do tempo de torração. Desta forma, todas as amostras foram torradas no mesmo tambor. As amostras de café verde de cada classe foram previamente pesadas e distribuídas em pacotes com 300 g cada.

Não foi realizado nenhum procedimento para controle da liberação de gás carbônico após a torração e moagem, conforme descrito abaixo.

Foram realizados três tipos de torra: clara (americana), expresso (média) e escura para cada tipo de classe do café. O tempo final de cada tipo de torra foi determinado por meio de testes preliminares de acordo com treinamento realizado na cafeeira INCOFEX e no Centro de Treinamento e Armazenagem (CENTREINAR). Em cada dia foi feito um tipo de torra para as três classes de café, ininterruptamente. Ao final de cada torra, os grãos foram homogeneizados e ficaram armazenados em vasilhames de polietileno com tampa (capacidade $5 \mathrm{~kg}$ ) e revestidos internamente com papel alumínio, por sete dias, à temperatura ambiente.

O efeito da temperatura de torração provoca diversas alterações nos grãos de café: expansão do grão, alterações na estrutura e coloração $[1,8]$. Estes efeitos são devidos principalmente às reações pirolíticas que provocam alterações nos compostos orgânicos do grão cru gerando produtos, tais como: açúcares caramelizados, ácidos voláteis, carbonilas voláteis, $\mathrm{CO}_{2}$ e sulfetos.

O café torrado (torra escura) tornou-se poroso e quebradiço. O açúcar e os gases desenvolvidos durante o processo promoveram a expansão dos grãos em conseqüência das mudanças provocadas pelo calor ao gás carbônico. Essa expansão pôde ser comprovada ao se armazenar os grãos após a torração, sendo maior à medida que os grãos permaneciam por mais tempo no aquecimento, ou seja, da torra clara para a torra escura.

Durante as torrações escuras, os lipídeos são liberados sob forma de fumaça vermelha, e é comum haver ruptura da estrutura celular com liberação de óleos quimicamente ligados que, uma vez livres, movimentam-se através do grão, umedecendo sua superfície [ 1, 5, 7]. Isto não ocorreu nas amostras de café estudadas, uma vez que foi utilizado um binômio tempo/temperatura abaixo daquele que permitisse o desprendimento de óleo dos grãos, principalmente na torra escura.

O binômio tempo $\mathrm{x}$ temperatura utilizado para cada tipo de torra variou de 160 a $170^{\circ} \mathrm{C}$ por 8 a 9 minutos para a torra clara, de 220 a $223^{\circ} \mathrm{C}$ por 10 a 11 minutos para a torra expresso, e de 220 a $230^{\circ} \mathrm{C}$ por 11 a 12 minutos para a torra escura. Houve um aumento no binômio tempo $\mathrm{x}$ temperatura em relação a cada tipo de torra. Vale ressaltar que por terem sido usados grãos classificados como "bica corrida”, havia grãos graúdos e miúdos dentro da mesma classe de café, o que pode ter levado à variação no tempo de torra das amostras.

O ponto de torração foi avaliado através de subseqüentes retiradas de amostras durante o processamento, visando à observação visual da cor do café, de acordo com cada tipo de torra.

Os grãos torrados foram moídos em moinho elétrico e passados em peneira de 20 mesh. O café em pó foi armazenado em vidros com capacidade para $300 \mathrm{~g}$ e, posteriormente, identificados.

Para evitar a perda dos constituintes voláteis e a oxidação pelo oxigênio e pela luz foi colocada uma camada de nitrogênio na superfície interior dos vidros sobre o pó. Em seguida, os vidros foram tampados e selados com pasta de silicone e cobertos por papel alumínio.

A relação entre tipo de torra e perda de peso dos grãos de café pode ser observada na Tabela 1. A maior perda de peso ocorreu para a torra escura, como era esperado, uma vez que os grãos de café ficaram mais tempo sob o efeito de altas temperaturas. As perdas de peso para os grãos de café submetidos às torras expresso e escura estavam dentro dos valores citados por MATIELLO [8] (13 a 20\%).

TABELA 1 - Relação entre o tipo de torra e a perda de peso dos grãos de café

\begin{tabular}{lccc}
\hline $\begin{array}{l}\text { Tipo de } \\
\text { classe/ torra }\end{array}$ & $\begin{array}{c}\text { Peso } \\
\text { in } \text { natura } \mathbf{( g )}\end{array}$ & $\begin{array}{c}\text { Peso } \\
\text { torrado } \mathbf{( g )}\end{array}$ & $\begin{array}{c}\text { Perda de peso } \\
\text { após torração (\%) }\end{array}$ \\
\hline Mole/clara & 3600 & 3255 & 9,6 \\
Dura/clara & 3600 & 3185 & 11,5 \\
Rio/clara & 3600 & 3225 & 10,4 \\
Mole/expresso & 3600 & 3088 & 14,2 \\
Dura/expresso & 3600 & 3095 & 14,0 \\
Rio/expresso & 3600 & 3100 & 13,8 \\
Mole/escura & 3600 & 2968 & 17,5 \\
Dura/escura & 3600 & 2995 & 16,7 \\
Rio/escura & 3600 & 2973 & 17,4 \\
\hline
\end{tabular}

Durante a estocagem dos grãos de café torrado, pode ocorrer perda de aroma e sabor de "café fresco", devido à oxidação lipídica e à degradação de muitos compostos inerentes ao aroma típico do café [10]. Como as amostras de café ficaram por um pequeno período armazenadas em grãos torrados (sete dias) e depois em embalagens totalmente lacradas, acredita-se que isto não deva ter ocorrido.

\section{3 - Análise tempo-intensidade}

Para a realização desta análise foi utilizado o programa Sistema de Coleta de Dados Tempo-Intensidade (SCDTI), desenvolvido pelo Laboratório de Análise Sensorial da Faculdade de Engenharia de Alimentos da Universidade 
Estadual de Campinas - UNICAMP. Este programa opera em ambiente Windows, em computadores IBM-PC ou compatíveis e permite a coleta e manipulação dos dados Tempo-Intensidade. Por meio de uma interface gráfica na forma de escala, o provador treinado indica por meio do mouse a intensidade do estímulo que ele está analisando. Os dados são armazenados, podendo ser utilizados na forma de gráficos e analisados futuramente. No gráfico, são sempre representados os valores de tempo no eixo horizontal e os valores de intensidade no eixo vertical. No decorrer da análise, são apresentadas mensagens de aviso do início de cada etapa da análise, com instruções ao provador sobre a ação a ser realizada [4].

\section{4 - Preparo e apresentação das amostras}

A análise Tempo-Intensidade foi realizada no laboratório de Computação do Departamento de Tecnologia de Alimentos da Universidade Federal de Viçosa (DTA/UFV).

As amostras de café foram preparadas no laboratório de Análise Sensorial do Departamento de Tecnologia de Alimentos da Universidade Federal de Viçosa (DTA/UFV), utilizando-se café e água deionizada na proporção de $6 \%$, conforme recomendado por CARVALHO et al. [5], tendo como instrumento operacional uma cafeteira elétrica da marca Wallita. A cada infusão, eram preparados no máximo $500 \mathrm{~mL}$ de cada amostra e armazenados em garrafas térmicas, permanecendo neste local por no máximo 90 minutos.

A avaliação das amostras de café foi feita, utilizandose $30 \mathrm{~mL}$ de cada amostra servidas em xícaras de fundo preto previamente codificadas com número de três dígitos, e oferecido um copo de água com capacidade para $200 \mathrm{~mL}$ entre as análises. Todos os provadores foram orientados a engolir todo o volume da amostra a cada avaliação.

\section{5 - Características sensoriais avaliadas}

Os atributos avaliados pela análise Tempo-Intensidade foram previamente discutidos com a equipe final da Análise Descritiva Quantitativa (ADQ) das mesmas amostras, realizada em estudo anterior. A partir de um consenso da equipe, foram definidos os seguintes atributos como representativos das amostras de café: gosto amargo, sabor fermentado e sabor queimado.

\section{6 - Seleção dos provadores}

Foram recrutados os provadores que tinham participado da Análise Descritiva Quantitativa (ADQ) e novos provadores com habilidade em trabalhar com computador. Para os provadores que não tinham participado da Análise Descritiva Quantitativa (ADQ), foi realizada uma pré-seleção através de testes triangulares. Oito provadores foram pré-selecionados de acordo com o interesse, disponibilidade em participar da análise e com os resultados dos testes triangulares.
Logo após, foi realizado um treinamento composto, basicamente, por duas etapas: apresentação e treinamento dos atributos a serem analisados e familiarização dos provadores com o programa SCDTI.

Na primeira etapa, os provadores foram treinados em relação a cada atributo a ser avaliado, utilizando os mesmos padrões de referência da Análise Descritiva Quantitativa (Tabela 2), em três sessões. Foram realizados testes preliminares para definição do tempo total de duração de cada estímulo com os provadores selecionados. Utilizou-se uma amostra que pudesse ter em maior intensidade todos os atributos a serem analisados (rio/escura) na análise Tempo-Intensidade, em três repetições por provador para cada atributo.

TABELA 2 - Padrões de referência mínimo e máximo para os três atributos avaliados

\begin{tabular}{lc}
\hline Termo descritor & Referências \\
\hline Sabor fermentado & Nenhum: amostra mole/clara \\
& Forte: amostra rio zona/escura \\
Sabor queimado & Nenhum: amostra mole/clara \\
& Forte: amostra mole/escura \\
Gosto amargo & Fraco: amostra mole/clara \\
& Forte: amostra mole/escura adicionada \\
de $0,1 \%$ de cafeína
\end{tabular}

A familiarização com o programa SCDTI, segunda etapa, foi realizada em três sessões, nas quais cada provador pôde conhecer o programa SCDTI e realizar simulações com o produto (café) nos atributos anteriormente treinados. Todos os procedimentos em relação ao programa SCDTI foram padronizados nesta etapa.

Enfim, foi realizada a seleção final dos provadores por meio de um teste preliminar, utilizando o programa SCDTI para as amostras de café dura/escura, mole/expresso e rio/clara. A análise para cada atributo foi realizada separadamente com o tempo total de duração do estímulo pré-determinado anteriormente. As amostras foram apresentadas de forma monádica, com três repetições para cada uma.

Foi realizada análise de variância (ANOVA), com duas fontes de variação (repetição e amostra) por provador, para cada parâmetro da curva TI, com a finalidade de se obter informações sobre a repetibilidade e o poder de discriminação destes provadores. Foram excluídos os provadores que apresentaram probabilidade de $\mathrm{F}$ (amostra) maior ou igual a 0,50 ou probabilidade de $\mathrm{F}$ (repetição) menor ou igual a 0,05 em pelo menos um dos parâmetros.

\section{7 - Avaliação das amostras}

Dos oito provadores que participaram do treinamento, seis foram selecionados, sendo novamente treinados para melhor padronização dos testes.

As amostras de café foram analisadas de forma monádica e aleatorizada por sorteio, para cada atributo em três repetições. 
Em todas as avaliações, os provadores receberam $30 \mathrm{~mL}$ de cada amostra a ser avaliada em xícaras de fundo preto, codificadas com algarismos de três dígitos. Cada provador foi orientado a seguir as instruções do programa SCDTI e colocar todo o volume da amostra na boca. As instruções básicas eram para que ao sinal sonoro emitido pelo computador, juntamente com o sinal gráfico, o provador colocasse a amostra na boca e em determinado tempo a ingerisse. Durante este procedimento, o provador deveria registrar toda intensidade de estímulo percebido através do mouse em escala na tela.

A temperatura do café servido aos provadores foi em média $60^{\circ} \mathrm{C}$.

Os tempos de espera inicial, tempo de residência da amostra na boca, tempo após a ingestão (tempo total de duração dos testes) foram padronizados e seguidos rigorosamente por todos os provadores. Os tempos de espera e permanência da amostra na boca foram de dez segundos e o tempo total de duração dos testes foi 40 segundos para o gosto amargo, 40 segundos para o sabor fermentado e 35 segundos para o sabor queimado. Uma escala estruturada de nove pontos foi utilizada em que $0=$ nenhum, $4,5=$ moderado e $9=$ forte.

As informações das curvas da análise Tempo-Intensidade de cada amostra para cada parâmetro foram salvas e armazenadas em disco rígido e analisadas, utilizandose procedimentos do pacote estatístico SAS (Statistical Analysis System - SAS Institute Inc., North Carolina, USA), versão 8.0, licenciado para a Universidade Federal de Viçosa, 2002 [11].

Os parâmetros coletados a partir das curvas TempoIntensidade para cada atributo foram: tempo para atingir a intensidade máxima (TImáx), intensidade máxima do estímulo (Imáx), tempo correspondente ao ponto onde a intensidade máxima começa a declinar (Td), tempo de duração da intensidade máxima (Platô), área sob a curva (Área) e tempo total de duração do estímulo (Ttot).

\section{8 - Análise dos resultados}

O experimento foi realizado seguindo um esquema fatorial $3^{2}$, com os fatores grau de torra em três níveis (clara, expresso e escura) e classe de bebida, também em três níveis (mole, rio e dura). As nove combinações (tratamentos) foram dispostas em delineamento inteiramente casualizado, em três repetições.

Dos dados coletados para cada parâmetro, foi realizada a ANOVA de dois fatores (amostra e provador) e a interação destes para cada parâmetro. Foi aplicado teste de Tukey para comparação das médias das amostras, ao nível de 5\% de significância, além da Análise de Componentes Principais (ACP). Para tal, foram utilizados programas do pacote estatístico SAS (Statistical Analysis System - SAS Institute Inc., North Carolina, USA), versão 8.0, licenciado para a Universidade Federal de Viçosa, 2002.

O resultado da análise de cada amostra em cada atributo foi feito através das médias e demonstrado através das curvas finais com os valores médios dos provadores para cada parâmetro avaliado.

\section{3 - RESULTADOS E DISCUSSÃO}

Dos oito provadores que participaram de todas as etapas do teste Tempo-Intensidade, seis foram selecionados. A equipe sensorial foi composta por provadores com faixa etária de 20 a 35 anos, sendo uma mulher e cinco homens.

\section{1 - Gosto amargo}

De acordo com a ANOVA (Análise de Variância Univariada) dos dados de Tempo-Intensidade para os seis parâmetros avaliados nas amostras de café para o gosto amargo, a interação amostra* provador $(p>0,05)$ foi não significativa em todos os parâmetros da curva Tempo-Intensidade. Houve diferença significativa $(p \leq 0,05)$ entre as amostras em todos os parâmetros, exceto para o platô $(\mathrm{p}=0,7474)$.

As Figuras 1 e 2 são uma projeção dos resultados obtidos da Análise de Componentes Principais (ACP) para as amostras de café em relação ao atributo amargo. $\mathrm{Na}$ representação gráfica por ACP, cada eixo (componente principal) explica uma porcentagem da variação total entre as amostras. Para o gosto amargo, a porcentagem de variância explicada foi de $66 \%$ para o primeiro componente e de $21 \%$ para o segundo, portanto $87 \%$ da variação total para os componentes principais quanto aos parâmetros da curva Tempo-Intensidade, o que demonstra uma ótima explicação da variação ocorrida entre as amostras, em relação aos parâmetros das curvas Tempo-Intensidade analisados.

O primeiro componente principal sugere semelhança entre as amostras de café, formando dois grupos distintos: o primeiro com as três amostras de torra escura, rio/expresso e dura/expresso, e o segundo com as três amostras de torra clara e mole/expresso.

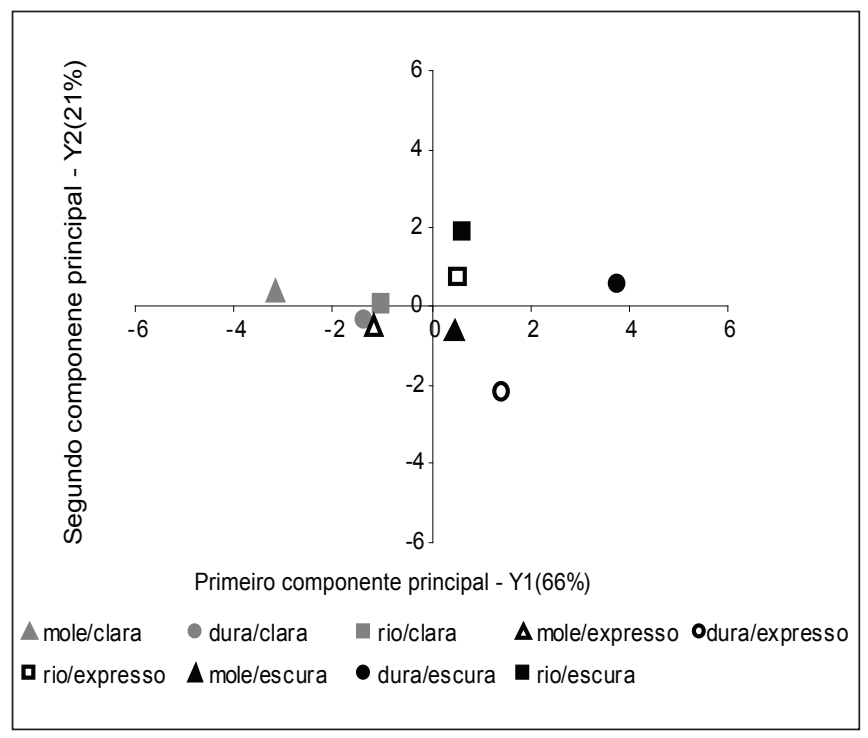

FIGURA 1 - Dispersão das amostras de café em relação aos dois primeiros componentes principais, gosto amargo 


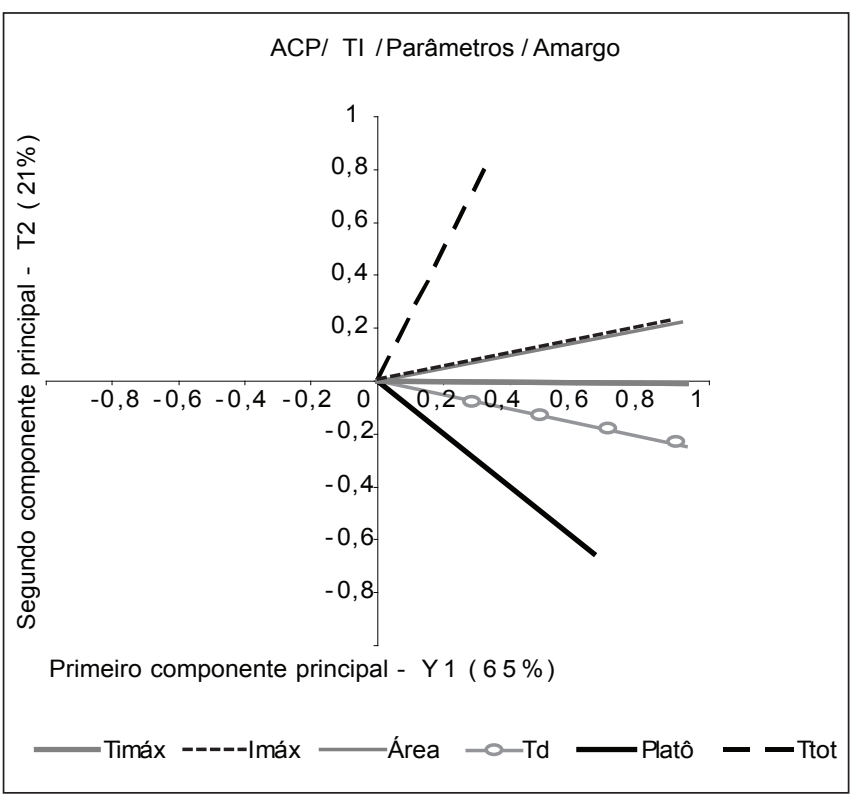

FIGURA 2 - Correlações entre os parâmetros sensoriais e os dois primeiros componentes principais, gosto amargo

TABELA 3 - Correlações (coeficiente de correlação de Pearson) entre os parâmetros e os dois primeiros componentes principais, gosto amargo

\begin{tabular}{|c|c|c|c|c|}
\hline \multirow{3}{*}{ Parâmetros } & \multicolumn{4}{|c|}{ Componentes principais } \\
\hline & \multicolumn{2}{|c|}{ Y1 } & \multicolumn{2}{|c|}{ Y2 } \\
\hline & $r$ & $P$ & $r$ & $p$ \\
\hline TImáx & 0,93 & 0,00 & $-0,01$ & 0,97 \\
\hline Imáx & 0,90 & 0,00 & 0,21 & 0,57 \\
\hline Área & 0,92 & 0,00 & 0,22 & 0,56 \\
\hline $\mathrm{Td}$ & 0,94 & 0,00 & $-0,26$ & 0,49 \\
\hline Platô & 0,65 & 0,05 & $-0,65$ & 0,05 \\
\hline Ttot & 0,33 & 0,37 & 0,82 & 0,00 \\
\hline
\end{tabular}

r: coeficiente de correlação de Pearson; p: nível de significância; TImáx: tempo de intensidade máxima; Imáx: Intensidade máxima; Área: área sob a curva; Td: tempo correspondente ao ponto, em que a intensidade máxima começa a declinar; Platô: tempo de duração da intensidade máxima em segundos; Ttot: tempo total de duração do estímulo
Na Figura 2 encontram-se as correlações entre os parâmetros da curva Tempo-Intensidade e os dois primeiros componentes principais. Os parâmetros TImáx, Imáx, Área e Td estão correlacionados ( $\mathrm{p} \leq 0,10$ ), Tabela 3 , com o primeiro componente principal. O parâmetro Platô correlaciona-se com os dois primeiros componentes principais, sendo que Ttot correlaciona-se com o segundo componente.

As Figuras 1 e 2 sugerem que a amostra dura/escura apresenta tempo de intensidade máxima (TImáx), intensidade máxima (Imáx), área sob a curva e o tempo de duração da intensidade máxima (Td) do gosto amargo em maior intensidade. Já a amostra mole/clara apresenta menor intensidade destes parâmetros. Em relação ao tempo total de duração do gosto amargo, a análise de componente principal sugere que a amostra rio/escura apresenta maior intensidade. E a amostra dura/expresso apresenta maior tempo de duração da intensidade máxima do gosto amargo.

As informações sugeridas pela Análise de Componentes Principais podem ser observadas nos resultados do teste de Tukey (Tabela 4). Para os parâmetros Platô e Ttot não houve diferença significativa entre as amostras para o gosto amargo. Ou seja, a duração da intensidade máxima do gosto amargo bem como a duração total do estímulo não diferiu ( $p>0,05)$ entre as nove amostras de café analisadas. Foram obtidos valores médios maiores para Imáx para as amostras de torra escura e valores menores para as de torra clara. Isto ocorreu uma vez que, quanto maior o tempo no qual os grãos de café são expostos ao calor, maior será a intensidade do gosto amargo.

As curvas Tempo-Intensidade para o gosto amargo das nove amostras de café percebidas por todos os provadores são apresentadas na Figura 3. A intensidade e o tempo total de percepção do gosto amargo foi maior para as amostras de torra escura, menor para as de torra clara e intermediária para as amostras de torra expresso. Estes resultados seguem a tendência de que quanto maior o tempo de torra, maior a percepção do gosto amargo.

TABELA 4 - Médias da equipe sensorial para cada parâmetro das curvas Tempo-Intensidade para o gosto amargo ${ }^{1}$

\begin{tabular}{|c|c|c|c|c|c|c|c|c|c|}
\hline \multirow{3}{*}{$\begin{array}{l}\text { Parâmetros da curva } \\
\text { Tempo-intensidade }\end{array}$} & \multicolumn{9}{|c|}{ Amostras } \\
\hline & \multicolumn{3}{|c|}{ Clara } & \multicolumn{3}{|c|}{ Expresso } & \multicolumn{3}{|c|}{ Escura } \\
\hline & Mole & Dura & Rio & Mole & Dura & Rio & Mole & Dura & Rio \\
\hline $\begin{array}{l}\text { TImáx } \\
\text { (tempo de intensidade máxima) }\end{array}$ & $12,95 b$ & $13,94 a b$ & $13,85 a b$ & $13,61 \mathrm{ab}$ & $14,40 a b$ & $13,32 \mathrm{ab}$ & $13,74 a b$ & $15,10 a$ & $14,02 \mathrm{ab}$ \\
\hline $\begin{array}{l}\text { Imáx } \\
\text { (intensidade máxima) }\end{array}$ & $4,42 \mathrm{e}$ & $5,02 \mathrm{de}$ & $5,29 \mathrm{cde}$ & $5,69 \mathrm{bcd}$ & $5,79 \mathrm{bcd}$ & $5,90 \mathrm{bcd}$ & $6,50 \mathrm{abc}$ & $7,25 a$ & $6,62 \mathrm{ab}$ \\
\hline $\begin{array}{l}\text { Área } \\
\text { (área sob a curva) }\end{array}$ & $67,68 d$ & $87,55 \mathrm{~cd}$ & $87,74 \mathrm{~cd}$ & $97,37 \mathrm{bc}$ & $99,88 b c$ & $100,47 \mathrm{bc}$ & $108,81 \mathrm{abc}$ & $132,89 a$ & $117,22 a b$ \\
\hline $\begin{array}{l}\text { Td } \\
\text { (tempo correspondente ao ponto onde a } \\
\text { intensidade máxima começa a declinar) }\end{array}$ & $16,24 b$ & $17,14 a b$ & $17,19 a b$ & $16,89 a b$ & $18,56 a$ & 17,73ab & $17,45 a b$ & 18,93a & $17,24 a b$ \\
\hline $\begin{array}{l}\text { Platô } \\
\text { (tempo de duração da intensidade máxima } \\
\text { em segundos) }\end{array}$ & $3,28 a$ & $3,19 a$ & $3,33 a$ & $3,28 a$ & $4,16 a$ & $3,40 a$ & $3,70 a$ & $3,82 a$ & $3,16 a$ \\
\hline $\begin{array}{l}\text { Ttot } \\
\text { (tempo total de duração } \\
\text { do estímulo) }\end{array}$ & $37,11 a$ & $34,76 a$ & $36,12 a$ & $34,01 \mathrm{a}$ & $34,52 a$ & $37,82 a$ & $35,07 a$ & $38,35 a$ & $38,45 a$ \\
\hline
\end{tabular}

${ }^{1}$ Médias seguidas de pelo menos uma mesma letra, na mesma linha, não diferem significativamente entre si ( $\left.p>0,05\right)$, pelo teste de Tukey. 


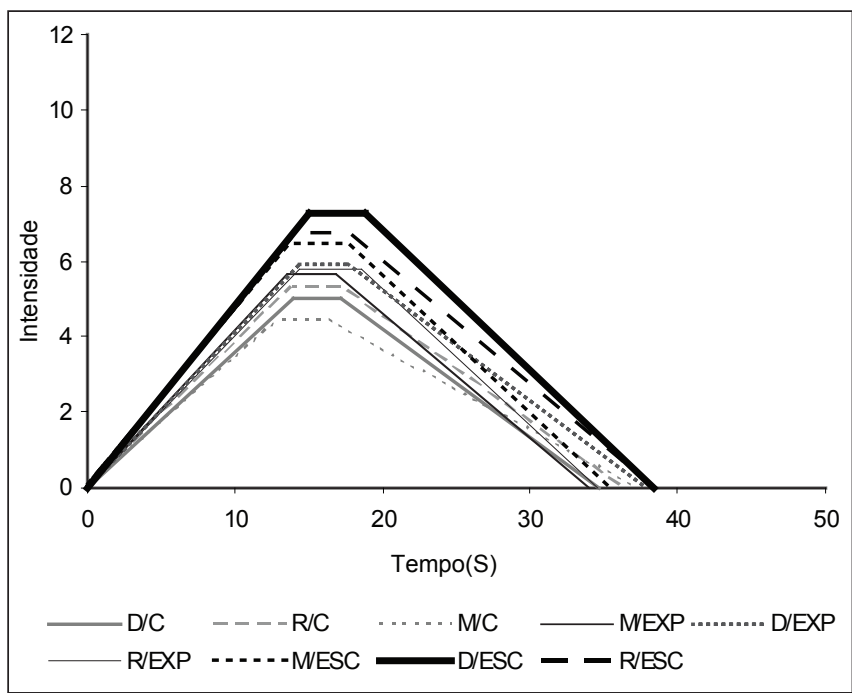

FIGURA 3 - Curvas Tempo-Intensidade características do gosto amargo para as três classes de café (mole, dura e rio) nos diferentes tipos de torra (clara, expresso e escura) referente à média dos 6 provadores selecionados

\section{2 - Sabor fermentado}

A ANOVA (Análise de Variância Univariada) dos dados de Tempo-Intensidade para os parâmetros avaliados nas amostras de café para o sabor fermentado mostra que, para o parâmetro Área, houve efeito significativo da interação amostra*provador. Assim, para este parâmetro, o teste para efeito de amostras (tratamento) foi realizado novamente, utilizando o quadrado médio da interação amostra* provador como denominador ( $\mathrm{F}$ versus interação). Quanto às amostras de café, não houve diferença significativa $(p>0,05)$ entre as mesmas para todos os parâmetros, exceto para Platô.

As Figuras 4 e 5 são uma projeção dos resultados obtidos na Análise de Componentes Principais (ACP) para as nove amostras de café. Na representação gráfica por ACP, cada eixo (componente principal) explica uma porcentagem da variação total entre as amostras. Para o sabor fermentado, o primeiro componente principal explica $42 \%$ da variância total entre as amostras, enquanto o segundo explica $34 \%$. Os dois primeiros componentes principais explicam, portanto, $76 \%$ da variância entre os parâmetros da curva Tempo-Intensidade.

A Figura 5 representa as correlações entre os parâmetros da curva Tempo-Intensidade para o sabor fermentado e os dois primeiros componentes principais. Os parâmetros TImáx, Td, Platô e Ttot estão correlacionados com o primeiro componente principal ( $\mathrm{p} \leq 0,10)$, Tabela 5 , sendo que Imáx e Área estão correlacionados com o segundo.

As Figuras 4 e 5 sugerem que a amostra rio/expresso é a que apresenta a maior área e a maior intensidade máxima (Imáx) para o sabor fermentado. Já a mole/expresso apresenta maior tempo de percepção da intensidade máxima do sabor fermentado (Platô) e maior tempo para a intensidade máxima começar a declinar (Td). Sugerem também que as amostras mole/escura e dura/expresso necessitam de

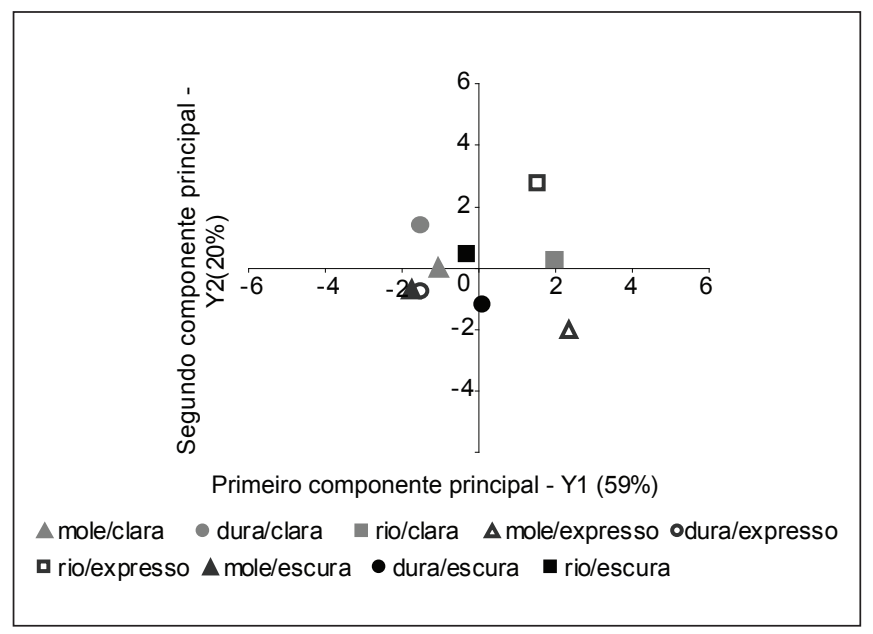

FIGURA 4 - Dispersão das amostras de café em relação aos dois primeiros componentes principais, sabor fermentado

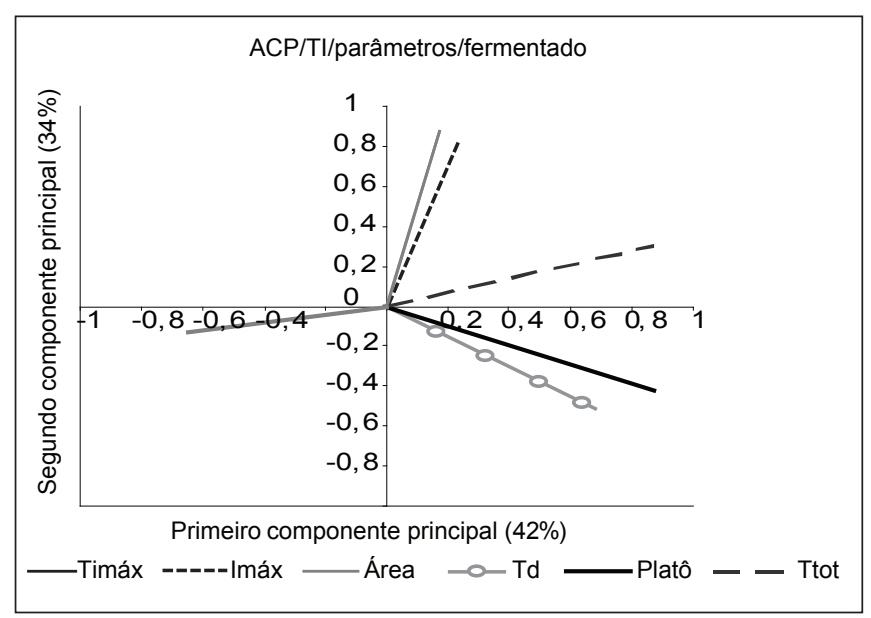

FIGURA 5 - Correlações entre os parâmetros sensoriais e os dois primeiros componentes principais para o sabor fermentado

TABELA 5 - Correlações (coeficiente de correlação de Pearson) entre os parâmetros e os dois primeiros componentes principais, sabor fermentado

\begin{tabular}{|c|c|c|c|c|}
\hline \multirow{3}{*}{ Parâmetros } & \multicolumn{4}{|c|}{ Componentes principais } \\
\hline & \multicolumn{2}{|c|}{ Y1 } & \multicolumn{2}{|c|}{ Y2 } \\
\hline & $\mathbf{r}$ & $\mathbf{p}$ & $\mathbf{r}$ & $\mathbf{p}$ \\
\hline TImáx & $-0,65$ & 0,05 & $-0,13$ & 0,72 \\
\hline Imáx & 0,24 & 0,53 & 0,85 & 0,00 \\
\hline Área & 0,17 & 0,64 & 0,87 & 0,00 \\
\hline $\mathrm{Td}$ & 0,68 & 0,04 & $-0,51$ & 0,15 \\
\hline Platô & 0,87 & 0,00 & $-0,42$ & 0,25 \\
\hline Ttot & 0,87 & 0,00 & 0,30 & 0,42 \\
\hline
\end{tabular}

r: coeficiente de correlação de Pearson; p: nível de significância; TImáx: tempo de intensidade máxima; Imáx: Intensidade máxima; Área: área sob a curva; Td: tempo correspondente ao ponto onde a intensidade máxima começa a declinar; Platô: tempo de duração da intensidade máxima em segundos; Ttot: tempo total de duração do estímulo

maior tempo para atingir a intensidade máxima (Imáx) para o sabor fermentado.

As informações sugeridas pela Análise de Componentes Principais podem ser observadas nos resultados do teste de Tukey (Tabela 6). Não houve diferença significativa entre os parâmetros Td e Ttot para os três tipos de torra. 
TABELA 6 - Médias da equipe sensorial para cada parâmetro das curvas Tempo-Intensidade para o sabor fermentado ${ }^{1}$

\begin{tabular}{|c|c|c|c|c|c|c|c|c|c|}
\hline \multirow{3}{*}{$\begin{array}{l}\text { Parâmetros da curva } \\
\text { Tempo-intensidade }\end{array}$} & \multicolumn{9}{|c|}{ Amostras } \\
\hline & \multicolumn{3}{|c|}{ Clara } & \multicolumn{3}{|c|}{ Expresso } & \multicolumn{3}{|c|}{ Escura } \\
\hline & Mole & Dura & Rio & Mole & Dura & Rio & Mole & Dura & Rio \\
\hline $\begin{array}{l}\text { Imáx } \\
\text { (intensidade máxima) }\end{array}$ & $6,13 a b$ & $6,74 a b$ & $6,46 a b$ & $5,58 b$ & $6,32 \mathrm{ab}$ & $10,04 a$ & $6,18 a b$ & $6,02 a b$ & $6,46 a b$ \\
\hline $\begin{array}{l}\text { Área } \\
\text { (área sob a curva) }\end{array}$ & $99,89 a$ & $118,72 a$ & $111,88 a$ & $98,37 a$ & $104,15 a$ & $119,48 a$ & $96,02 a$ & $97,07 a$ & $105,19 a$ \\
\hline $\begin{array}{l}\text { Td } \\
\text { (tempo correspondente ao ponto } \\
\text { onde a intensidade máxima } \\
\text { começa a declinar) }\end{array}$ & $16,66 a$ & $17,02 a$ & $18,04 a$ & $18,50 a$ & $17,77 a$ & $17,37 a$ & $17,12 a$ & $17,89 a$ & $16,89 a$ \\
\hline $\begin{array}{l}\text { Ttot } \\
\text { (tempo total de duração do } \\
\text { estímulo) }\end{array}$ & $35,70 a$ & $36,08 a$ & $38,34 a$ & $37,01 a$ & $34,81 a$ & $37,64 a$ & $35,09 a$ & $36,77 a$ & $36,37 a$ \\
\hline
\end{tabular}

${ }^{1}$ Médias seguidas de pelo menos uma mesma letra na mesma linha não diferem significativamente entre si ( $\left.p>0,05\right)$, pelo teste de Tukey

A Imáx de percepção do sabor fermentado foi maior para a amostra rio/expresso.

As curvas Tempo-Intensidade para o sabor fermentado das nove amostras de café percebidas por todos os provadores são apresentadas na Figura 6. A intensidade de percepção e duração da percepção do sabor fermentado foi maior para a amostra rio/expresso. Estes resultados estão relacionados à classe do café, rio, que tem como definição ser uma bebida com sabor forte e desagradável, lembrando iodofórmico ou ácido fênico. A amostra que teve menor intensidade do sabor fermentado foi a mole/expresso. A

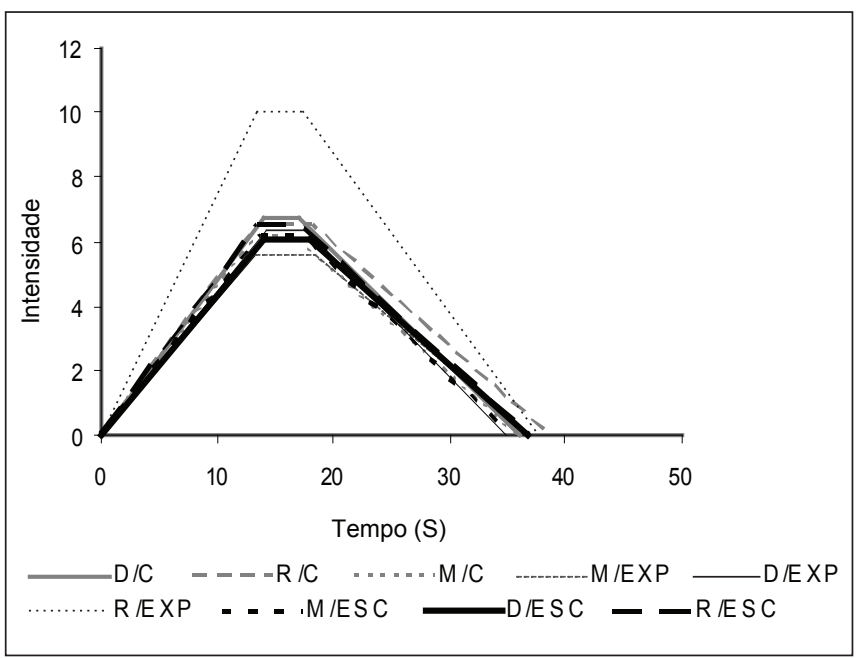

FIGURA 6 - Curva Tempo-Intensidade característica do sabor fermentado para as três classes de café (mole, dura e rio) nos diferentes tipos de torra (clara, expresso e escura) referente à média dos 6 provadores selecionados classe de café mole possui uma qualidade, em termos de bebida, superior à do rio.

\section{3 - Sabor queimado}

Os parâmetros Imáx e Área da interação amostra*provador foram significativos $(\mathrm{p} \leq 0,05)$. Desta forma, o teste para efeito de amostras (tratamento) foi realizado novamente, utilizando o quadrado médio da interação amostra*provador como denominador ( $\mathrm{F}$ versus interação) para estes parâmetros. Há diferença significativa entre as amostras de café apenas em relação a Imáx e Área.

As Figuras 7 e 8 são uma projeção dos resultados obtidos da Análise de Componentes Principais (ACP) para as amostras de café. Na representação gráfica por ACP, cada eixo (componente principal) explica uma porcentagem da variação total entre as amostras. Para o sabor queimado, o primeiro componente principal explica $58 \%$ da variância total entre os parâmetros, enquanto o segundo componente explica $23 \%$. Os dois primeiros componentes principais explicam a maior parte da variância (81\%) entre as amostras quanto aos parâmetros da curva Tempo-Intensidade.

As correlações entre os parâmetros da curva TempoIntensidade e os dois primeiros componentes principais são representadas na Figura 8. Os parâmetros TImáx, Imáx, Área, Td e Ttot estão correlacionados com o primeiro componente principal $(\mathrm{p} \leq 0,10)$, Tabela 7 . O parâmetro Platô correlacionou-se com o segundo componente.

A configuração espacial, na Figura 7, sugere dois grupos com amostras de café semelhantes entre si (torra escura e 
TABELA 7 - Correlações (coeficiente de correlação de Pearson) entre os parâmetros e os dois primeiros componentes principais, sabor queimado

\begin{tabular}{lccccc}
\hline & \multicolumn{5}{c}{ Componentes principais } \\
\cline { 2 - 6 } Parâmetros & \multicolumn{2}{c}{ Y1 } & $\mathbf{p}$ & $\mathbf{r}$ & $\mathbf{p}$ \\
\cline { 2 - 6 } & $\mathbf{r}$ & 0,79 & 0,01 & $-0,33$ & 0,37 \\
Timáx & 0,93 & 0,00 & 0,26 & 0,49 \\
Imáx & 0,93 & 0,00 & 0,24 & 0,52 \\
Área & 0,75 & 0,01 & 0,52 & 0,14 \\
Td & $-0,48$ & 0,18 & 0,77 & 0,01 \\
Platô & 0,61 & 0,07 & $-0,37$ & 0,32 \\
Ttot &
\end{tabular}

r: coeficiente de correlação de Pearson; p: nível de significância; TImáx: tempo de intensidade máxima; Imáx: intensidade máxima; Área: área sob a curva; Td: tempo correspondente ao ponto onde a intensidade máxima começa a declinar; Platô: tempo de duração da intensidade máxima em segundos; Ttot: tempo total de duração do estímulo

dura/expresso, e as amostras de torra clara, rio/expresso e mole/expresso).

As Figuras 7 e 8 sugerem que o grupo das amostras de torra escura e dura/expresso caracteriza-se por apresentar em maior intensidade todos os parâmetros, exceto Platô. As amostras mole e rio/clara se caracterizam por apresentar maior tempo de duração da intensidade máxima do sabor queimado.

As informações sugeridas pela Análise de Componentes Principais podem ser observadas nos resultados do teste de Tukey (Tabela 8). Apenas para os parâmetros Imáx e Área houve diferença significativa $(\mathrm{p} \leq 0,05)$ entre as amostras de café.

As curvas Tempo-Intensidade para o sabor queimado das nove amostras de café percebidas por todos os provadores são apresentadas na Figura 9. A intensidade (Imáx) da percepção do sabor queimado foi maior para as amostras de torra escura, e menor para as de torra clara. Estes resultados eram esperados, em função do tempo de torração.

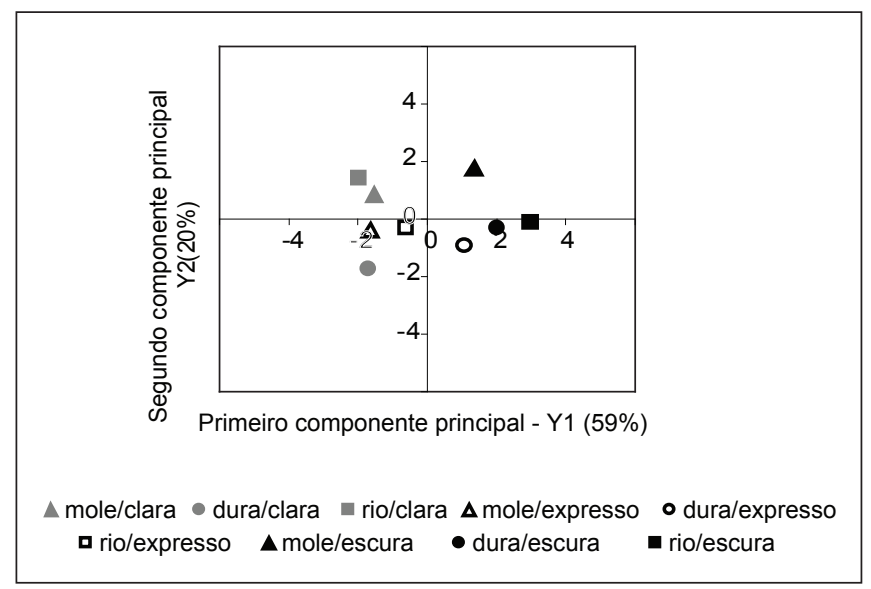

FIGURA 7 - Dispersão das amostras de café em relação aos dois primeiros componentes principais, sabor queimado

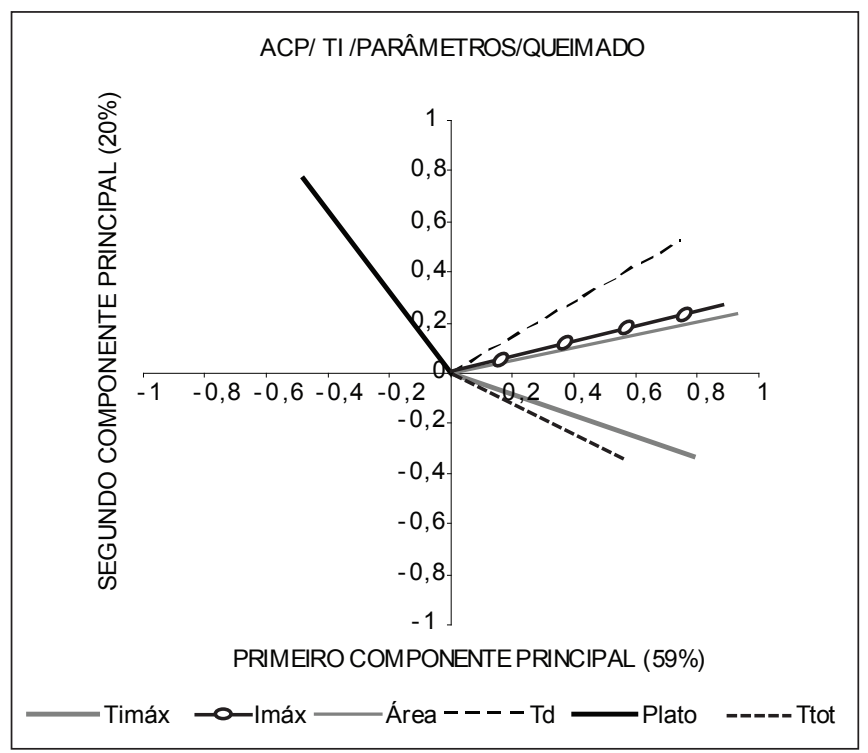

FIGURA 8 - Correlaçõe s entre os parâmetros sensoriais e os dois primeiros componentes principais

TABELA 8 - Médias da equipe sensorial para cada parâmetro das curvas Tempo-Intensidade sabor queimado1

\begin{tabular}{|c|c|c|c|c|c|c|c|c|c|}
\hline \multirow{3}{*}{$\begin{array}{l}\text { PARÂMETROS DA CURVA } \\
\text { TEMPO-INTENSIDADE }\end{array}$} & \multicolumn{9}{|c|}{ AMOSTRAS } \\
\hline & \multicolumn{3}{|c|}{ CLARA } & \multicolumn{3}{|c|}{ EXPRESSO } & \multicolumn{3}{|c|}{ ESCURA } \\
\hline & MOLE & DURA & RIO & MOLE & DURA & RIO & MOLE & DURA & RIO \\
\hline $\begin{array}{c}\text { TImáx } \\
\text { (tempo de intensidade máxima) }\end{array}$ & $13,20 a$ & $13,35 a$ & $12,47 a$ & $12,69 a$ & $13,39 a$ & $12,98 a$ & $13,30 \mathrm{a}$ & $13,68 a$ & $13,70 a$ \\
\hline $\begin{array}{c}\text { Imáx } \\
\text { (intensidade máxima) }\end{array}$ & $4,60 d$ & $4,44 d$ & $5,03 \mathrm{~cd}$ & $5,09 \mathrm{~cd}$ & $6,14 \mathrm{abcd}$ & $5,57 \mathrm{bcd}$ & $7,45 a$ & $6,71 \mathrm{abc}$ & 7,30ab \\
\hline $\begin{array}{c}\text { Área } \\
\text { (área sob a curva) }\end{array}$ & $70,75 d$ & $66,84 d$ & $79,35 \mathrm{~cd}$ & $83,56 \mathrm{bcd}$ & $97,63 a b c d$ & $84,82 \mathrm{bcd}$ & $120,32 \mathrm{ab}$ & $112,17 a b c$ & $124,60 a$ \\
\hline $\begin{array}{l}\text { Td } \\
\text { (tempo correspondente ao ponto onde a } \\
\text { intensidade máxima começa a declinar) }\end{array}$ & $16,79 a$ & $15,63 a$ & $16,37 a$ & $16,02 a$ & $16,62 a$ & $16,35 a$ & $16,93 a$ & $16,91 \mathrm{a}$ & $17,04 a$ \\
\hline $\begin{array}{c}\text { Platô } \\
\text { (tempo de duração da intensidade } \\
\text { máxima em segundos) }\end{array}$ & $3,58 a$ & $3,40 a$ & $3,89 a$ & $3,33 a$ & $3,22 a$ & $3,36 a$ & $3,62 a$ & $3,25 a$ & $3,30 a$ \\
\hline $\begin{array}{c}\text { Ttot } \\
\text { (tempo total de duração do estímulo) }\end{array}$ & $31,49 a$ & $32,99 a$ & $33,08 a$ & $32,11 a$ & $33,61 a$ & $32,80 a$ & $32,36 a$ & $33,25 a$ & $34,07 a$ \\
\hline
\end{tabular}

1Médias seguidas de pelo menos uma mesma letra na mesma linha não diferem significativamente entre si $(p>0,05)$, pelo teste de Tukey. 


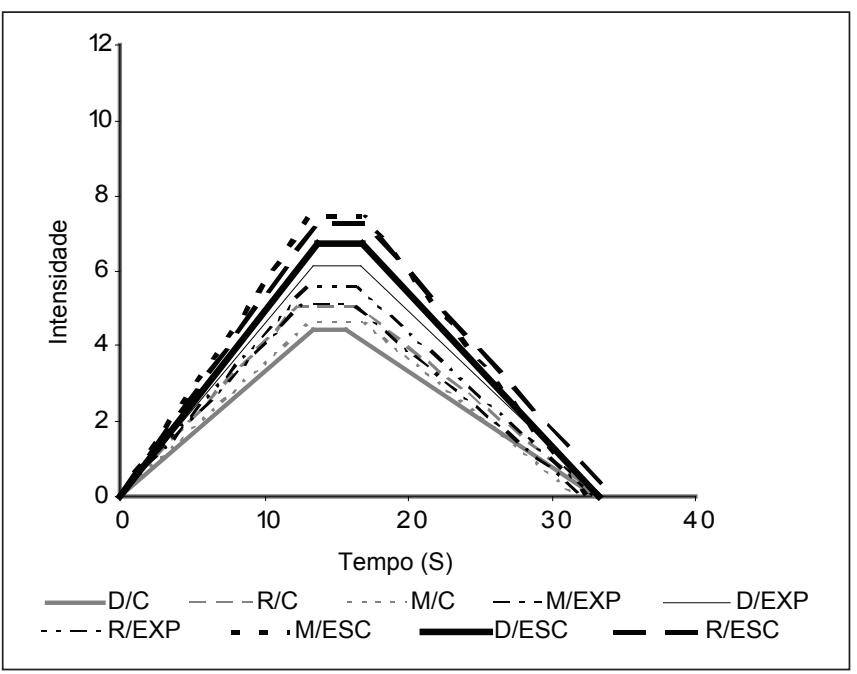

FIGURA 9 - Curva Tempo-Intensidade característica do sabor queimado para as três classes de café (mole, dura e rio) nos diferentes tipos de torra (clara, expresso e escura) referente à média dos 6 provadores selecionados

\section{4 - CONCLUSÕES}

De acordo com as curvas Tempo-Intensidade para o gosto amargo e sabores fermentado e queimado, as nove amostras da bebida café apresentaram um comportamento inicial semelhante, em que a percepção do estímulo teve início ao entrar em contato com a mucosa oral e aumentou após a ingestão.

As curvas Tempo-Intensidade para os atributos amargo e queimado comprovam os resultados obtidos na Análise Descritiva Quantitativa (ADQ), uma vez que os mesmos tiveram maiores valores de intensidade máxima (Imáx) e tempo de duração do estímulo (Ttot) para as amostras de torra escura.

Os parâmetros das curvas Tempo-Intensidade que diferenciaram as amostras para o gosto amargo foram tempo de intensidade máxima (TImáx), intensidade máxima (Imáx), área sob a curva (Área) e tempo correspondente ao ponto onde a intensidade máxima começa a declinar (Td). Portanto, formaram-se três grupos distintos em função do tipo de torra.

Para o sabor fermentado, os parâmetros intensidade máxima (Imáx) e tempo de duração da intensidade máxima em segundos (Platô) diferenciaram as amostras, sendo que rio/expresso apresentou maior Imáx.

O sabor queimado teve comportamento semelhante ao obtido pelo gosto amargo em relação ao tipo de torra. Porém, teve como diferencial entre as nove amostras da bebida café, os parâmetros intensidade máxima (Imáx) e área sob a curva (Área).

\section{5 - REFERÊNCIAS BIBLIOGRÁFICAS}

[1] ARAÚJO, J.M.A. Química de Alimentos: Teoria e Prática. 2a ed. Viçosa. UFV. 2001. 416 p.

[2] CAIXETA, G.Z.T. Economia cafeeira, mercado de café, tendências e perspectivas. In: I Encontro sobre Produção de Café com Qualidade. Viçosa, MG: UFV, Departamento de Fitopatologia, 1999. 259 p.

[3] CARDELLO, H.M.A.B. e DAMÁSIO, M.H. Análise Tempo-Intensidade. Boletim da Sociedade Brasileira de Ciência e Tecnologia de Alimentos, v. 30, n. 2, p. 156-165, julho/dezembro, 1996.

[4] CARDELlO, H.M.A.B., SILVA, M.A.A.P., DAMÁSIO, M.H. Programa Sistema de Coleta de Dados TempoIntensidade. Boletim sbCTA. v. 37. Suplemento. p. 54-60. 2003.

[5] CARVALHO, V.D.; CHAGAS, S.J.R.; CHALFOUN, S.M. Fatores que afetam a qualidade do café. Informe Agropecuário, v. 18, n. 187, p. 5-20, 1997.

[6] CLIFF, M. e HEYMANN, H. Development and Use of Time-Intensity Methodology for Sensory Evaluation: A review. Food Research International, v. 26, p. 375-385, 1993.

[7] ILLY, A. e VIANI, R. Espresso Coffee: the Chemistry of Quality. Academic Press. 1995. 243 p.

[8] Matiello, J.B. O Café do Cultivo ao Consume. São Paulo: Globo. 1991. 320 p.

[9] MENEZES, H.C. Relationship between the state of maturity of raw coffee beans and the isomers of caffeoylquinic acid. Food Chemistry, v. 50, p. 293-296, 1994.

[10] ORTOLÁ, M.D.; LONDOÑO, C.L; GUTIÉRREZ, C.L. e CHIRALT, A. Kinetic study of lipid oxidation in roasted coffee. Food Science and Technology International, v. 4, p. 67-73, 1998.

[11] SAS - Statistical Analysis System - SAS Institute Inc., North Carolina, USA. versão 8.0, licenciado para a Universidade Federal de Viçosa, 2002. 